\title{
PROACTA: A way to study the tendency to occur (TTO) of patient behaviours
}

\author{
Dieudonné Leclercq \\ Université de Liege, Sart-Tilman Building B 32, B-4000 Liege, Belgium
}

\begin{abstract}
Classical decision theory formulas have been combined with more recent theories from psycho-social origins (such as Rosenstock's health belief model, Fisbein's rational action theory, Bandura's concept of self-efficacy, Triandis' concern for the assessment of habits, etc.). A software, called PROACTA, enables simulations of actual cases. Currently, it is being tested in various backgrounds. It is orientated in order to help conceive intervening strategies, especially in the area of patient education. Examples of a case study are presented.
\end{abstract}

Keywords: Patient behaviour; Asșessment; Models; Health behaviour theories

\section{Introduction}

It is now largely acknowledged by patient education specialists that patients' behaviors are mainly influenced by subjective factors such as health beliefs [1,2], locus of control [3,4], perception of self-efficacy [5,6], perceived norms [7], etc. Generally, these factors are considered as independent variables in a model where the dependent variable is the behaviour itself [8]. Frequently, authors note that 'direct observation casts doubts on the consistency between patients' knowledge and beliefs and their real behaviour' [9] or that there exists a 'knowledge/behaviour gap' [10]. Conversely, other researchers 'showed that belief

* Corresponding author, Tel.: + 32 41662072; Fax: + 32 41662953; Internet: dleclerc@vml.ulg.ac.be. scores predicted (by discriminant analysis) compliance, especially in the long-term' [11]. The capacity of psycho-social models to enlighten comprehension and prediction of real behaviours is impaired by the lack of an intermediate layer, i.e. the estimation (by the patient himself, by the carers... and by a theoretical model) of the Tendency To Occur (TTO) of various actions. This implies the need to process a step beyond behaviour itself.

A metaphor may be needed here. The same kind of epistemological problem has arisen in the assessment of human knowledge. For years, under the (over) behaviouristic pressure to rely only on 'objectivity', only behaviours have been taken into account. For instance, only the student's answer (correct, incorrect) to a question is considered as a sound basis to estimate this person's competency in the tested domain. During the last 30 years, 
psychologists and educationists have started to ask the learner to add to his/her answer a confidence degree [12], enabling the researcher to compute an index of realism, and to distinguish several types of 'knowledge'. For instance, Hunt [21] distinguishes 4 types of a person's 'status of knowledge': (a) informed (correct answer and high confidence); (b) partially informed (correct answer and intermediate confidence); (c) uninformed (low confidence); (d) misinformed (incorrect answer and high confidence).

A series of researchers have developed 'objective ways to approach subjectivity', especially 'the human capacity of self-estimating' [12], based on De Finetti's basic assumptions [13]: 'Partial information exists. To detect it is necessary and feasible (p. 109)' and 'It is only subjective probability that can give an objective meaning to every response and scoring method (p. 111)'.

\section{Tendency to occur (TTOs) of behaviours in patient education}

It is suggested here that the same kind of approach should be adopted in the prediction or explanation or even prescription of patients' behaviour: try to estimate the 'tendency to occur' (TTO) of several behaviours, in order to distinguish various types of situations such as: (a) Clear-cut behaviour: the adopted one has a TTO largely superior to any other possible bchaviour and there is no inter-behaviour 'competition', no regret for the non-adopted ones. This is important if QOL (quality of life) is also considered. (b) Slightly better than the second: the behaviour adopted has a TTO equivalent to an other behaviour's TTO, so that one of them 'comes out' apparently on the basis of a random process. Actually, situational circumstances (what has just been seen, heard, experienced in the previous seconds or minutes) become of great predictory value. In this situation, regret may exist for the non-adopted competing behaviour and any opportunity to switch to it (in a compensation mechanism) would be seized by the patient. (c) Random choice: several behaviours have the same TTO and 'switching effects' may happen between more than 2 behaviours. (d) The least worst choice: in the dilemma situation, all courses of action are repulsive (because of negative consequences for instance). Therefore, the patient will 'minimise the losses'.

PROACTA is an attempt to assess the TTOs of various courses of action (behaviours) by 2 means: (a) a global one: (the patient's direct estimation) of each action's TTO; (b) an analytical one: the patient estimates a series of values for factors such as expected consequences, norms, self-efficacy, etc. On the basis of these data, the PROACTA software computes a TTO for each course of action. Three kinds of data can be compared, namely, the global TTOs, the analytical TTOs and the actual patient behaviour. This 'triangulation' enables validity and reliability studies.

\section{The underlying models of PROACTA}

\subsection{Classical decision theories}

From Aristotle to modern decision theorists like Von Neuman and Morgenstern, and Tversky, models have been provided to encapsulate an individual's decision into formulas. Basically, those formulas stand, on the one hand on the notion of utility (i.e. attractiveness or repulsiveness of given consequences) and, on the other hand, on the notion of probability (i.e. the likelihood that a given action would lead to a given consequence). Modern Decision Theory sees decision as the choice of the course of action that maximiscs the expected utility (i.e. the sum of the utilities of its consequences timed by their probabilities). From Bernouilli [14], utilities as well as probabilities are seen as subjective variables, i.e. they are given values by the decision-maker himself, independently of more 'objective' (or 'external') estimates.

\subsection{Additions from social research}

Lewin, from his 'Kriegslandschaff' article to his 'Field Theory' book $[15,16]$ argued that individual (and collective) behaviours are influenced by the dynamics of 'field forces', some being internal and others external, mainly social. More recent social scientists have contributed to explore these field forces. For instance, Fishbein and Ajzen [7], in 
their Rational Action Theory, stressed the importance of norms (perceived norms, nuanced by the 'tendency to conform' to them). Rotter [3] introduced the concept of 'locus of control', i.e. the feeling of having a personal control on the situation (internal attribution) or of being the object of external forces (external attribution), as well as the feeling of changeability (or not) of the situation. We will 'merge' this contribution with Bandura's [5,6], as well as with Ajzen and Madden's one $[17,18]$ in their 'Planned Behaviour Theory', where the locus of control is placed between the intention and the actual adoption of a behaviour. As a quasisymetrical concept, Rosenstock has suggested, in his Health Belief Model, that the perceived 'susceptibility' (i.e. personal tendency, or vulnerability) to a given consequence could also bias the choice of a course of action.

\subsection{Parcels of truth}

Each of the aforementioned contributors helps to better understand what may be the most complex object of study in the world: human thinking and behaviour processes. All of those contributions indicate how useful each of them is, their relative importance depending of the content, of the persons and of the circumstances. A more complete review of these contributions is to be found in Godin [19] who provides evidences of the relevance of all those theories (for instance, scholars such as Diclemente, Maddux, Stanley, Maddux and Strecher, Weinberg et al., etc. have provided experimental evidences of the relevance of the concept of self-efficacy promoted by Bandura. The same has been done by Becker to support Rosenstock's Health Belief Model. Fishbein's ideas about norms have been tested by Schlegel et al., Stutzman and Green, whereas Seibold and Ropper as well as Valuis have studied Fishbein's model in conjunction with Triandis' [20] one). Moreover, the individual is conscious of some factors affecting his/her behaviour and not conscious of some others. Several parts of those models overlap with the other models, so that, in the PROACTA approach described hereafter, we have kept only the non-overlapping concepts.

\subsection{Matching a set of gears}

Assuming that all the previous factors play a role in the selection of a given behaviour, it has been tried, in PROACTA, to combine them in order to study the effects of their interactions. PROACTA is nothing more than a simulation tool in which real or fictitious cases can be introduced. Its first utility is of a didactic nature, i.e. to help understand the theories themselves and their possible interrelations, i.e. a didactical goal. It is hoped, nevertheless, that PROACTA will densify the exchanges between theories and experimental (or experiential) data, to lead researchers about patients' or students' cases of behaviours.

As is the case with any simulation tool, PROACTA is based on a series of assumptions that deserve to be made explicit (in section 4, below).

\subsection{Action-driven and consequence-driven problems}

Some problems are 'action-driven', i.e. the decision-maker is faced with alternative actions (to smoke or not, to marry this person or to remain bachelor) and the problem is to document the consequences. Other problems are 'consequencesdriven'; i.e. the person knows the goals to achieve (get money, lose weight, recover from illness) but does not know how, and has to examine or imagine possible courses of actions. Depending on the situation, courses of actions or consequences will be defined first. Often, they are defined co-operatively.

\section{Assumptions or principles underlying PROACTA}

\subsection{Courses of actions}

Principle 1. Courses of actions will be considered as exclusive from each other, that forces to consider different combinations of elementary behaviours as different courses of actions. For instance, 'to stop smoking' is a different course of action from 'to stop smoking and start jogging'.

Principle 2. Qualitative changes in behaviour are a different course of action from quantitative changes. For instance, 'to eat less' is different 
from 'to eat the same amount as usual, but something different'.

Principle 3. 'No change' is a course of action. It may have negative (or positive) consequences.

\subsection{Consequences}

Principle 4. Different levels of quantitative changes can be considered as different consequences. For instance, losing $1 \mathrm{~kg}$ is a different consequence from losing $20 \mathrm{~kg}$. Their psychological consequence, i.e. satisfaction (or frustration), may not be in a linear relationship with their physical size. Therefore, they should be considered as distinct consequences.

\subsection{Tendencies to occur}

Principle 5. PROACTA computes the relative tendency to occur of each course of action, ranging from 0 to 100 , the action with the highest tendency receiving arbitrarily a value of 100 and the action with the lowest tendency receiving a value of 0 , the other actions having intermediate values (between these extremes), computed by 'interpolations'. The unit $(0-1$ and $0-100)$ of each parameter has been chosen arbitrarily to facilitate computing and graphic representation. This system hides the 'sign' of each course of action, i.e. whether the action is generally (i.e. all factors being combined) 'attractive' (positive) or 'repulsive' (negative). Those fundamental values can be obtained in the 'behind the stages' part of PROACTA, that keeps the original raw (positive and negative) values. It can happen that the person is facing a dilemma, when all the courses of action are repulsive (negative) and when the decision process is to chose the solution that minimises the losses (instead of maximising the gains). In other cases, the person is facing a 'happy choices' situation, where all choices come up with positive consequences.

Principle 6. The central table of PROACTA (P table) is the matrix of probabilities for each action to lead to each consequence and the $\mathrm{U}$ vector (i.e. the utilities of consequences). The sum, for each action, of the UP combination (multiplication) is the first 'provisory' estimates of tendencies to occur.

Principle 7. A 'U-generating' layer (optional) is constituted by factors 'explaining' the utilities, i.e. 'perceived susceptibility', 'norms about consequences' (e.g. 'My parents wish I lose a dozen kg'), 'relative weight of norms and personal opinion' about the desirability of consequences, etc. the combination of which result in the utility (or urgency or pressure).

Principle 8. A 'P-modifying' layer (optional) is constituted by 'self-efficacy regarding each action', norms about actions and the 'relative weights of norms and personal opinions' (in other terms 'Motivation to Conformity $=\mathrm{MC}$ ' vs. 'Motivation to Autonomy $=$ MA'). These factors can be defined before the central table, or be included by the interviewee in the Ps of the central table. In this last case, they have to be neutralised (see default values).

Principle 9. A 'final' layer is constituted by the 'strength of habits' (basically the frequency of each behaviour in the past), by situational 'circumstances favouring habits vs. intentions' for each action, and, finally, by the strength of habits vs. the strength of intentions in this kind of problem in general (values provided by experts).

Principle 10. The resulting prediction is the merging of several streams, even if it may appear as the end of a sequential process. The final scores do not appear at the end of the spreadsheet, but at the confluence of 'pressure' coming from habits (bottom of the spreadsheet) and 'pressure' coming from intentions (top of the spreadsheet).

Intermediate values of computed scores are displayed only to facilitate verification and to offer the basis of a graphic that should not be viewed as a sequential (from left to right) process even if lines in the graphic could be misleading in this respect.

Principle 11. Several PROACTA analyses may be performed on the same case study, e.g. for the successive steps of the development of a problem. An example of such 'evolution' will be provided hereafter and shows to what degree output varies according to inputs.

Principle 12. A 'self-validation' way of using PROACTA compares two types of data. On the one hand, a person is asked to analyse a single case he/she knows perfectly (because, for instance, it deals with a choice she/he had to make recently in his/her life, or because he/she was the physician in 
charge of the patient), in the terms of all the 'intermediate variables'. On the other hand, this same person is invited to provide also the 'final information', i.e. what actually happened (the course of action with the value 100 ), what was likely or unlikely to have happened too (the other courses of action) with a score between 100 and 0 .

Since the interviewee cannot combine the elementary data (to produce the final scores or predicted courses of actions or PCA) as PROACTA does, this sample of data (or actual courses of actions or ACA) offers an opportunity of testing the relevance (in terms of predictive efficiency of PCA vs. ACA) of PROACTA. Such an example will be provided hereafter. This approach has a drawback: intermediate values can be 'connected' in order to make PCA fit the final 'actual courses of actions'.

Principle 13. PROACTA can be ipsative, i.e. the interviewer may be the interviewee, and constitute a self-help in decision-making.

Principle 14. If a course of action has the value 100 and another the value 90 , there is a possibility that the second one occurs instead of the first, or that regret (nostalgia) will accompany the choice of the first one.

\section{The current version of PROACTA}

Currently PROACTA is just an EXCELL spreadsheet for research and didactic purposes. Soon, a patient interface, showing only visual analog scales as used in pain assessment [24] will be developed. The current PROACTA software has several characteristics and limitations: (a) There may be $1-6$ consequences, and from $2-4$ courses of action. If the problem actually has $<4$ courses of action, some of them (any one) should be 'repeated'. One course of action could be the 'no change' situation. (b) Grey areas have to be filled by the user. When designated, ' $\&$ cells' display appropriate 'comments' (the meaning and ranges of values for instance). (c) The resulting TTOs vary between 0 and 100 . They are relative values (where maximum is always 100 and minimum is always 0). Absolute values are also computed. They show whether some courses of action are repulsive whereas others are attractive. It may happen that all courses of action are repulsive (in the dilemma situation). The patient then chooses the 'least worst' behaviour. (d) Ignoring factors (neutral and default values). The list presented below of 'neutralising values' actually constitutes a list of default values that enables one to work on a simplified version of PROACTA. It also indicates in which order PROACTA should be filled: central and final layers first. Anterior and intermediate should come after, only if default options do not fit the situation.

Here is how factors can be neutralized

Perceived norms (PN): Giving them the same values as the personal attractiveness.

The relative weight (for each consequence) of the Motivation to Conform and the Motivation to Autonomy. Fixing them equal (50 and 50), i.e. weighted equally.

The personal susceptibility (or feeling of personal vulnerability) to each consequence: Fixing them all to the same value 1 (that means no more and no less than an average person).

The self-efficacy values (S) for each action: Fixing them all to the same value 1 (no more and no less than an average person).

The perceived norms values $(\mathrm{N})$ for each action: Fixing them all to the same value 1 (no more and no less than an average person).

The Motivation to Conform and Motivation to Autonomy balance values ( $\mathrm{MC}$ and MA): Fixing them equal ( 50 and 50 ) for each action.

\section{The PROACTA questionnaire}

Numerical values can be provided for PROACTA through a written (or oral) questionnaire. It will be displayed hereafter, filled with answers from an actual case study, documented by Dr Jacqueline Cronier, head of the Radiology and Echography department of the 'Centre Hospitalier de Puteaux' in France. (See Table 1).

\subsection{The analytical approach}

The following values have been introduced in a PROACTA spreadsheet.

Question $a$. How would you introduce the problem, its origins and the main issues? 
Table 1

For economical reasons, a hospital is to be transormed; in particular, the surgery department will be replaced by a geriatric (less prestigious) one. What will the nurse do? Stay and convert to geriatrics or apply to an other hospital's surgery department? (Situation 1989)

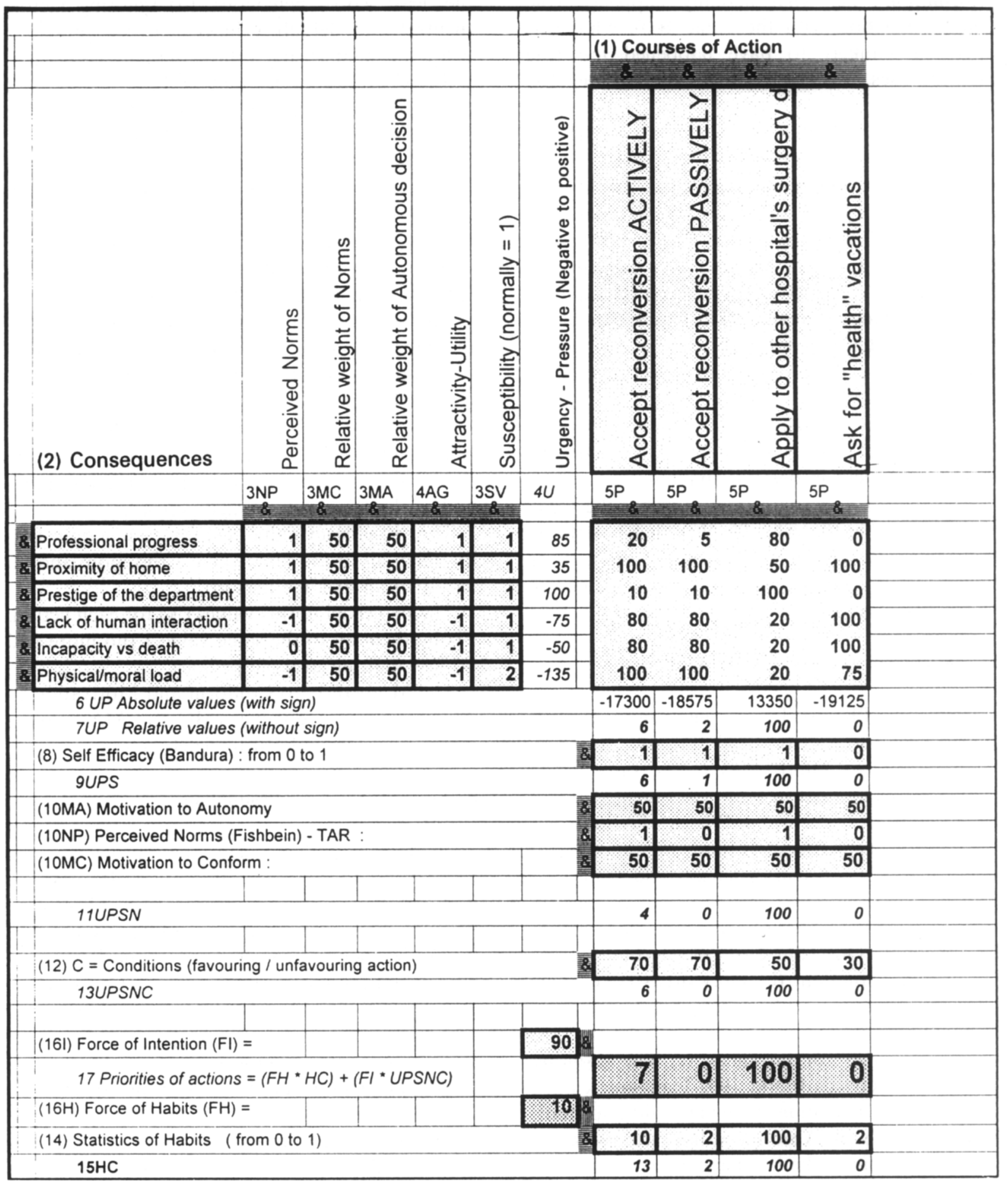


1989: A hospital is about to be transformed, for economical reasons; in particular, the surgery department will be phased out and replaced by a geriatric department. A nurse, specialised in surgery (the most honorific department to work in as a nurse) is faced with the decision to stay in the hospital and convert herself into a (less honorific) specialisation (geriatrics) or to apply to for relocation to surgery departments of other hospitals.

Question $b$. What are the Courses of Actions (CoA) to be considered? (and your self-efficacy S.E. for each of them?)

CoA $1=$ Actively accept reconversion to geriatrics (i.e. try to reach top qualification in this new domain) : 0

CoA $2=$ Passively accept reconversion to geriatrics (i.e. take no initiative, let things happen) 0.1

CoA $3=$ Apply to surgery departments of other hospitals : 1

CoA $4=$ Ask for 'health vacations' or technical unemployment : 0

Question $c$. What are the consequences to be considered and their attractiveness?

$\mathrm{Cl}=$ Professional progress : 1

$\mathrm{C} 2=$ Proximity of home : 0.5

$\mathrm{C} 3=$ Prestige of the department : 1

$\mathrm{C} 4=$ Lack of interaction (demented aged people) :

$-1$

C5 $=$ Incapacity of preventing people's death :

$-0.6$

C6 $=$ Heaviness of physical work-load : -0.8

Question $d$. What is the relative weight, in this problem of intention? : 90\%; of habits? : $10 \%$.

Question $e$. What is the outcome expectancies or probabilities of success (Ps) of each action vs. each consequence, here?

vs. professional progress: 'Accept actively' (20) is 4 times more likely than 'accept passively' (5) and 4 times less likely than 'apply to another hospital' $(80)$, whereas 'ask for vacations' is the certainty of no professional progress $(0)$.

vs. proximity of home: 'Apply to another hospital' is 2 times less likely (50) than other actions (100). vs. prestige: 'Apply to another hospital 'is 10 times more likely (100) than the 2 modes of acceptance (10). 'Ask for vacations' is the certainty of no prestige (0). vs. lack of human interaction: 'Acceptance' exposes 4 times more ( 80 ) and 'ask for vacations' 5 times more (100) to this danger than 'apply to another hospital' (20).

vs. incapacity vs. death: same as for lack of human interaction'.

vs. physical/moral load: 'Apply to another hospital' is 5 times less likely (20) to come up with physical load than accept (100), and 'ask for health vacations' is rather likely (75) to provoke moral load (culpability).

Question $f$. How frequent has been the action in the past $(\max =100)$ ?

10 To 'accept actively' (Mary is used to adapting, but in her domain);

2 To 'accept passively' (not at all her style);

100 To 'apply for change' (Mary often takes initiatives);

2 To 'ask for health interruption' (not at all her style).

Question $\mathrm{g}$. What are the perceived norms ? ( 0.5 being neutral):

0.8 To 'accept actively';

0.2 To 'accept passively';

1 To 'apply for change';

0.1 To 'ask for vacations'.

Question $h$. Are conditions in favour of a 'nonhabitual solution?' (Yes, if the score is $>50$, No, if $<50$ ):

70 To 'accept actively';

70 To 'accept passively';

50 To 'apply for change';

30 To 'ask for health interruption';

Question $i$. What is your susceptibility to each consequence (and why)?

$\mathrm{Cl}=$ Professional progress : 1 (No more, no less than anyone)

$\mathrm{C} 2$ = Proximity of home : 0.7 (Several hospitals are in the other neighbourhood)

C3 = Prestige of the department : 1 (No more, no less than...)

$\mathrm{C} 4=$ Lack of interaction : 1 (Idem)

$\mathrm{C} 5=$ Incapacity of preventing death : 1 (Idem)

C6 $=$ Physical workload : 1.5 (A little less resistant than average, i.e. more susceptible to suffer from workload). 
Table 2

The nurse has followed specialised courses on geriatrics and discovered the physical and psychological approaches of ageing persons. She is no longer afraid of demented persons. Conditions to convert to geriatrics are fulfilled, even if she is still nostalgic of the past (Situation 1991).

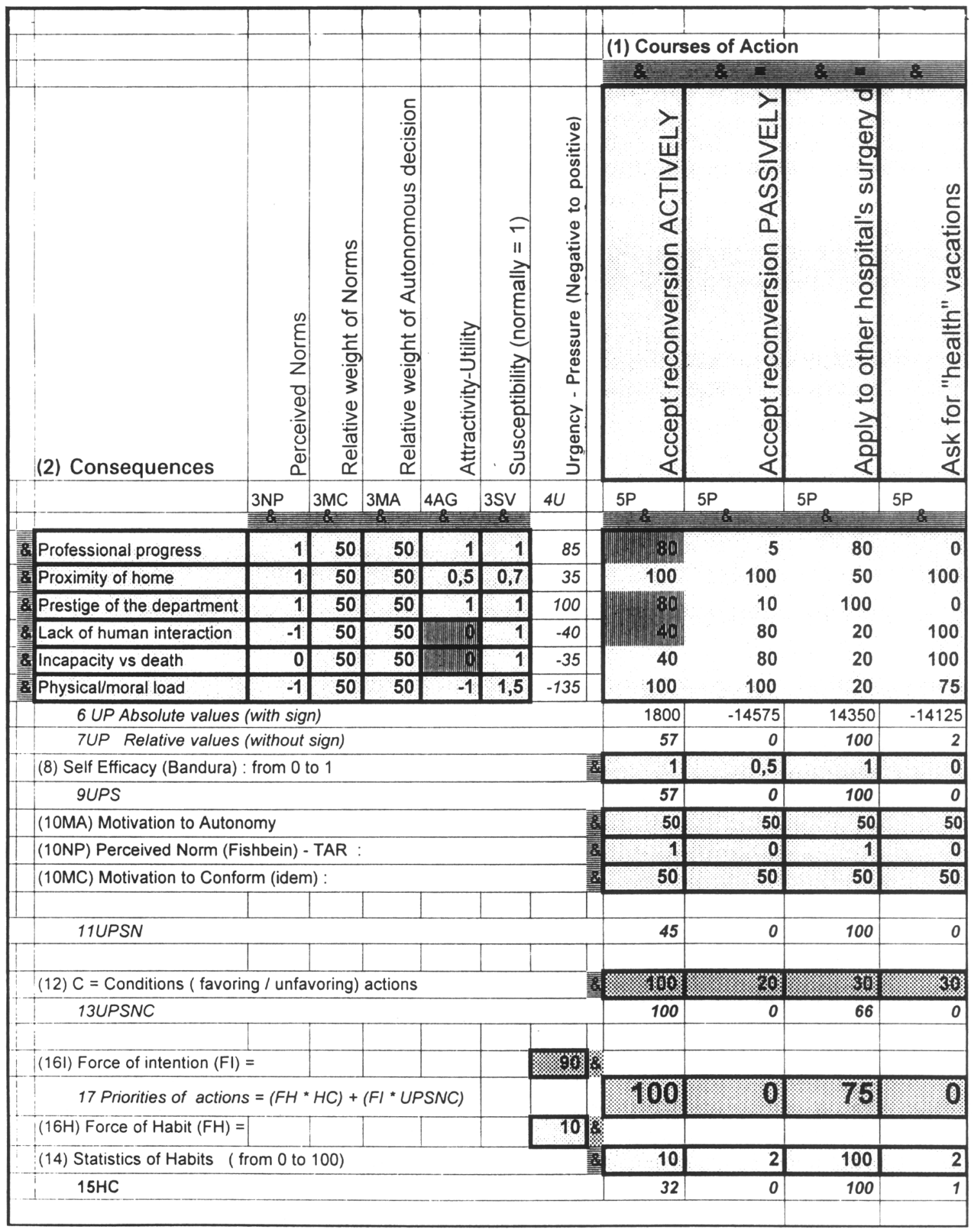


Table 3

The nurse has followed a training session for head nurses in geriatrics. The mourning process concerning her past activity is over. She has fully renounced to its technical aspects, and has discovered the organisational personnel management and institutional aspects of the new one (Situation 1993).

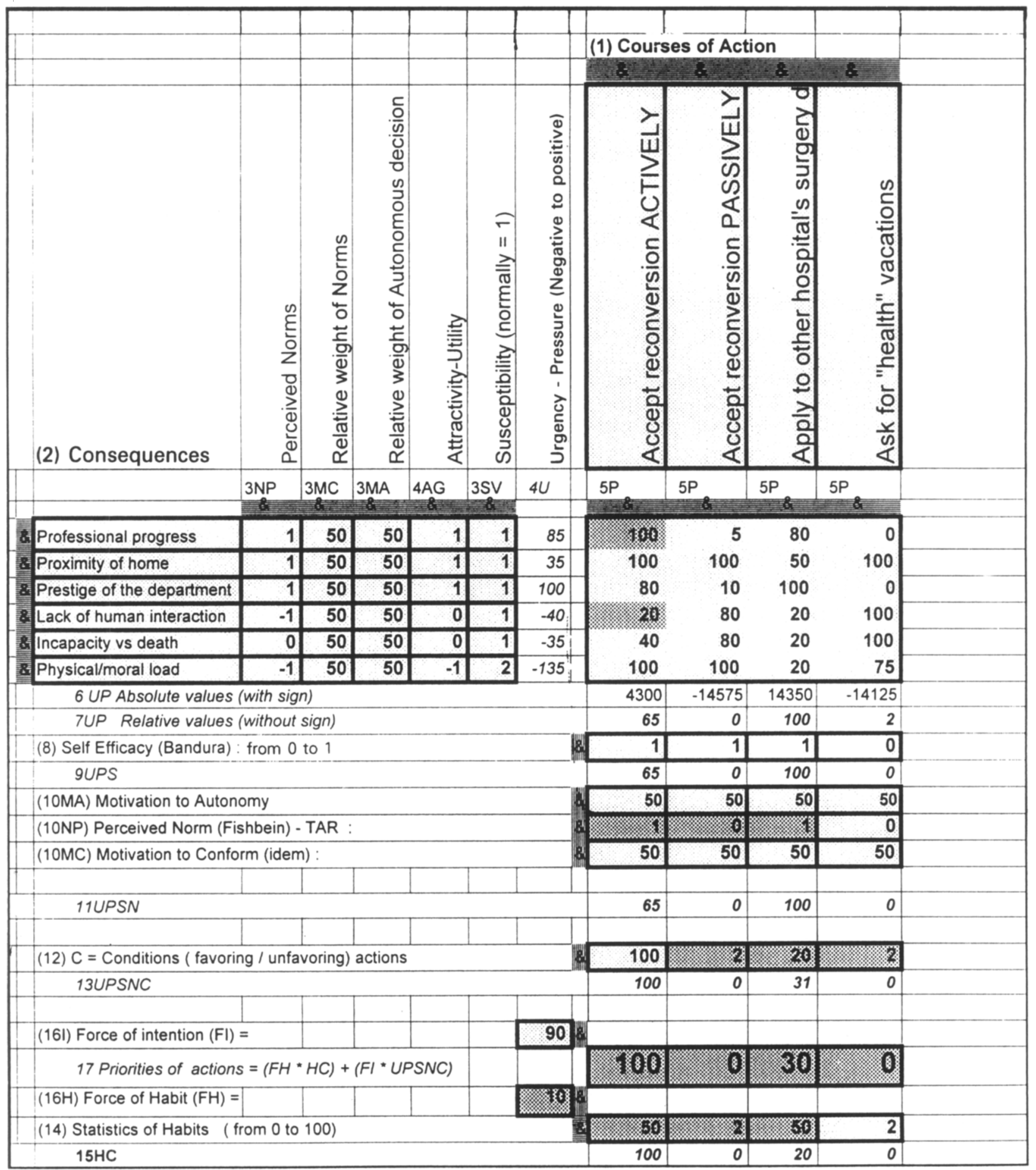


Question $j$. What are the norms about consequences (and their sources) and what are their relative weights: (Motivation to Conform (MC) versus Motivation to Autonomous behaviour (MA))? What is the balance?

MC/MA

$\mathrm{Cl}=$ Professional progress : 0.7 (My husband's opinion) $50 / 50$

$\mathrm{C} 2=$ Proximity of home : 0.5 (Idem) 50/50

C3 = Prestige of the department : 1 (Idem) 50/50

$\mathrm{C} 4=$ Lack of interaction : -0.5 (Idem) $50 / 50$

$\mathrm{C} 5=$ Incapacity of preventing death : -0.4 (Idem) 50/50

C6 $=$ Heaviness of physical workload : -1 (Idem) $50 / 50$

\subsection{The global question}

What should be PROACTA's results in terms of 'tendencies to occur' for each of the 4 Courses of Action (CoA): 5, 0, 100 and 0?

\subsection{The PROACTA computation}

The spreadsheet produces the following 'predictions' (from the analytical approach): 7, 0.3, 100, 0 . The proximity of the 2 last sets of values is not considered as a demonstration of the predictive validity of PRACTA, since the original data have been 'fine-tuned' by the author in the process of shaping PROACTA itself. From the numbers, action 3 (apply for another hospital) would have been chosen (no other possible action being competing with).

\subsection{Did changes occur in the situation?}

During 1989-1991, events happened (the nurse received courses on ageing persons, etc...), resulting in new values (in dark cells) and new behavioural tendencies, see the second PROACTA example where the 'expected final values' were $100,0,66,0$ (Table 2). Therefore, action 1 is now the more likely, but with regrets for action 2 (not adopted). In 1993, another major change occurred (orientation to team management), that gives rise to another (and last) PROACTA example, where the 'expected final values' were $100,0,25,0$. In this third step, action will be selected, but without regret (Table 3).

\section{Conclusions}

Although the case study that has been intensively developed here does not deal with a patient but with a nurse, PROACTA has been designed to fit various health education problems - patient education, drug consumption prevention, nutritional education, urgency help behaviour, AIDS prevention, etc. It seems obvious that PROACTA can be applied not only in (retro) descriptions but also in prediction, in dialogues, in decision-making, either in an ipsative (reflexive) way, or between a health professional and a patient, or for the health professional inner dialogue only, as a help to diagnosis. The scope is even broader than education or health: intentions of votes and collective decision-making, purchase decisions, partnership choices, vocational orientation, help of people in need of an urgent support, etc. Several simulations (with imaginary data) have been performed. Even if they do not predict actual behaviours, they constitute a stimulating way to investigate intervening factors and detect more specifically where and how deep is our ignorance, in Bachelard's terms: 'Reality is never what we could believe, but always what we should have thought'.

\section{Acknowledgements}

The author is grateful to the participants of his Seminar on 'Psychology of Learning' held at the Bobigny Faculty of Medicine (University of Paris XIII) in January 1994 as a part of the Master Courses in 'Health Pedagogy' (Co-ordinated by Prof. Dr. J.F. D'Ivernois), and, in particular, Mrs Darmour, Dr Ouss and Dr Trainard. A special contribution (the case illustrating this paper) is due to Dr Jacqueline Cronier.

\section{References}

[1] Rosenstock IM et al. Social Learning Theory and the Health Belief Model. Health Educ Q 1988; 15: 175-183.

[2] Rosenstock IM. Historical Origins of the Health Belief Model. Health Educ Monogr 1974; 2: 328-335.

[3] Rotter J. Generalised expectancies for internal versus external control of reinforcement. Psychol Monogr 1966; 80: (1, whole No. 609). 
[4] Pieri M, Biondi T, Lisi F, Nannetti L, Marsilii A. Relationship between diabetic patient's education and locus of control. In: Assal and Golay eds, 1994; 42.

[5] Bandura A. Social Learning Theory. Englewood Cliffs, NJ: Prentice Hall, 1977

[6] Bandura A. Self-Efficacy: Toward a Unifying Theory of Behaviour Change. Psychol Rev 1977; 84: 191-215

[7] Fishbein M, Ajzen I. Belief Attitude, Intention and Behaviour. An Introduction to Theory and Research. Don Mills Ont: Addison-Wesley, 1975.

[8] Day JL, Bodmer CW, Dunn O. Factors influencing selfmanagement and glycaemic control in insulin dependent diabetes mellitus, Abstract No. 25, In: Assal J-Ph, Golay A eds. Abstracts of Presentations at Patient Education 2000. Patient Educ Couns, 23, Suppl., 1994

[9] Bloise D, Gargano A, Tremaroli R, Ceci M, Fraticelli E, Falluca F, Maldonato A. Prevention of foot lesions in diabetic patients. Decreased peripheral sensitivity. Results of specific education, Abstract No. 24, In: Assal J-Ph, Golay A eds. Abstracts of Presentations at Patient Education 2000. Patient Educ Couns, 23, Suppl., 1994.

[10] Decham-Leroux C. Etiological bclicfs in diabetic paticnts and life-cycle, Abstract No. 33, In: Assal J-Ph. Golay A eds. Abstracts of Presentations at Patient Education 2000. Patient Educ Couns, 23, Suppl.. 1994.

[11] Nurymberg C, Kreitler S. Psychological determinants of compliance in short and long-term type 2 diabetic patients. Abstract No. 35, In: Assal J-Ph, Golay A eds. Abstracts of Presentations at Patient Fducation 2000. Patient Educ Couns, 23, Suppl., 1994.

[12] Leclercq D. Validity, Reliability and Acuity of Self-Assessment in Educational Testing. In: Leclercq and Bruno eds, 1993; 114-131.

[13] De Finetti B. Mcthods for discriminating levels of partial knowledge concerning a test item. Br J Math Stat Psychol 1965; 18: 87-123. De Finetti B. Dans quel sens la théorie de la décision est-elle et doit-elle être normative? in F.N.R.S. (Colloque du), La décision. Paris 1959; 159 170.

[14] Bernouilli D. Exposition of a new theory on the measurement of risk (English translation of 'Specimen theorial novea de mensura sortis'. Commentarii academiae scientiarium imperialis Petropolitanae, 10 et $1573,5, \mathrm{pp}$. 175-192), by Louise Sommer. Economica, 22-23-26, 1954.

[15] Lewin K. Field Theory in Social Science. New York: Harper. 1951

[16] Lewin K. Kriegslandschaff. Z Agenwandte Psychol 1917; 12: 446-447.

[17] Ajzen I, Madden TJ. Prediction of Goal-Directed Behaviour: Attitudes, Intentions and Perceived Behavioural Control. J Exp Soc Psychol 1986; 22: 453-474.
[18] Ajzen I. From intentions to Actions: A Theory of Planned Behaviour. In: Kuhl J, Beclmann J eds. ActionControl: From Cognition to Behaviour. Heidelberg: Springer, 1985; 11-39.

[19] Godin G. Les fondements psychosociaux dans l'étude des comportements reliés à la santé, in Santé-Société (Collection Promotion et Santé), 2: La promotion de la santé: concepts et stratégies d'action, Ministère de la Santé et des Services Sociaux, Québec, Canada, ISBN, 2-55020184-1, 1988; 86.

[20] Triandis HC. Interpersonal Behaviour. Monterey, CA Brook/Cole, 1977.

[21] Hunt DP. Human self-assessment - theory and application to learning and testing. In: Leclercq and Bruno eds, $1993 ; 177-189$.

[22] Ajzen I, Fishbein M. Understanding Attitudes and Predicting Social Behaviour. Fnglewood Cliffs, NJ: PrenticeHall, 1980.

[23] Allais M. La psychologie de l'homme rationnel devant le risque: la théorie et l'expérience. J Soc Stat 1953; 94; $43-73$.

[24] Allaz AF, Binyet S, Desmeules J, Dayer P. Illness behaviour and pain coping in chronic pain patients. Abstract 28. In: Assal J-Ph, Golay A eds. Abstracts of Presentations 2000. Patient Educ Couns, 23, Suppl., 1994.

[25] Assal J-Ph, Golay A. Abstracts of Presentations at Patient Education 2000, International Congress on Treatment of Chronic Diseases, Patient Educ Counsel 23: Suppl. 1, June 1944, Flsevier.

[26] Bandura A. Social Foundations of Thought and Action: A Social Cognitive Theory. Englewood Cliffs, NJ: Prentice Hall, 1986.

[27] Bayes T. An essay Toward Solving a Problem in the Doctrine of Chance. Phil Trans R Soc, London, 1763.

[28] Irwin WS, Smith WA. Value, Cost and Information as Determiners of Decision. J Exp Psychol 1957; 54: 229232.

[29] Leclercq D, Bruno J. eds. Item Banking: Interactive Testing and Self-Assessment, NATO ASI Series F.: Computer and Systems Sciences, 112. Heidelberg: Springer-Verlag, 1993.

[30] Leclercq D, Sigaudes D. Vouloir, savoir, se voir, choisir et pouvoir. Hygie 6, 2: 33-36.

[31] Lindley LW. Making Decisions. London: Wiley, 1964.

[32] Luce RD. Individual Choice Behaviour. New York: Wiley, 1959.

[33] Luce RD, Raiffa H. Games and Decision. New York: Wiley, 1966.

[34] McClelland Studies in Motivation. New York: Appleton, 1955.

[35] Radke $M$, Klisurich $D$. Experiments in changing food habits. J Am Diet Assoc 1947: 23: 403-409. 